\title{
DO CORPO AO ESPAÇO: CONTRIBUIÇÕES DA OBRA DE MAURICE MERLEAU-PONTY À ANÁLISE GEOGRÁFICA'
}

\author{
ELIAS LOPES DE LIMA²
}

\section{Introdução}

O presente artigo objetiva explicitar o quanto a obra de Merleau-Ponty pode ser relevante à investigação espacial em Geografia ou, mais precisamente, apontar algumas perspectivas que sua abordagem fenomenológica abre para uma leitura geográfica do espaço, sobretudo no que se refere ao estudo da paisagem. A paisagem, tal como convencionalmente é interpretada, parece encerrada pela atividade individual do sujeito, como apreensão de mundo isolada e independente de tudo e de todos, referendando assim um princípio solipsista, segundo o qual a única realidade possível é a de um $e u$ como sobrevôo de mundo. É como se o sujeito que apreende a paisagem se limitasse a um mero espectador. Neste sentido, a urgência de um sujeito de propriedades geográficas ganha corpo.

Merleau-Ponty visa, dentre outras preocupações, superar a dimensão espacial geométrica expressa na existência de um fora materializado na forma de um espaço como substância extensa contrastada com a existência de um eu interior cognoscente como pura substância pensante, presumindo, para tanto, um espaço como imagem do ser, um espaço existencial para o qual a existência é espacial (MERLEAU-PONTY, 2005:196). Este filósofo tenta romper com a idéia de um espaço único e absoluto, propondo um espaço como superfície da existência, apreendido por meio da experiência perceptível. Esquivando-se das estereotipias comuns quando se põe em causa corpo, espaço e tempo, Merleau-Ponty (1999:205) vai preferir dizer que o corpo é no espaço.

\footnotetext{
${ }^{1}$ O presente artigo deriva de dissertação de mestrado intitulada A Reinvenção da Corporeidade: $o$ cotejo entre a tradição moderna e a tradição indígena, do mesmo autor.

${ }^{2}$ Mestre em Geografia pelo PPGGEO/UFF; e-mail: eliasllopes@yahoo.com.br.
} 
Tal proposição, aparentemente simples, está para muito além de meramente admitir que o corpo é espaço ou que o corpo está situado no espaço. Dela deriva a conjectura segundo a qual a indissociabilidade entre tempo e espaço, expressos respectivamente em seus correlatos ontológicos ser e estar, apresentam-se como formas elementares da existência.

Consideramos que o maior mérito de Merleau-Ponty tenha sido reinserir o homem - por meio da percepção, experiência, sensibilidade e outras afecções somáticas - no centro de uma contradição secular, com isso tornando o corpo perceptivo um mediador de tais antinomias, agora não mais como termos inconciliáveis. É o caso da contradição entre sujeito e objeto, tempo e espaço, ser e aparência, consciência e coisa, razão e sensibilidade, dentre algumas outras, todavia, desta feita, passíveis de serem interpretadas como pares diferenciais que, como tais, complementam-se entre si.

\section{O espaço como experiência do corpo}

Seria prudente começar pelo que consideramos um expediente metodológico recorrente nos textos de Merleau-Ponty, a saber, a reversibilidade. À primeira impressão, a reversibilidade consiste na complementação de cada capacidade sensível por interdependência diferencial. Supõe-se que não á possível obter um sentido isolado dos outros, cada capacidade sensível requer sempre uma aderência, uma simultaneidade que confere significado aos demais sentidos. Assim, as sensações hápticas das mãos e da pele estão ligadas às percepções visuais e essas às faculdades auditivas e olfativas, assim como a impressão dos outros segmentos do corpo contribui para uma certa configuração unívoca dos sentidos conformando um mesmo gesto sensível e inteligível. Para essa inseparabilidade vai concorrer uma experiência da diferenciação em que as faculdades sensíveis trocam de papéis sem que anulem sua condição originária. Elas se tornam reversíveis.

Disso resulta a possibilidade de reversão e de reconversão de uma linguagem que pode ser estendida a outros planos relacionais. "Possibilidade de reportar e de revirar segundo a qual o pequeno mundo privado de cada um não se justapõe àquele de todos os outros mas é por ele envolvido, colhido dele, constituindo, todos juntos” (MERLEAU-PONTY, 2005:138). Em última análise, portanto, a reversibilidade consiste numa circularidade de atos e de ações que afetam ao corpo e ao outro reciprocamente, articulando-os numa conjunção de corpos a suscitar uma espacialidade entendida como corporeidade dos corpos. ${ }^{3}$ Assim há uma reversibilidade daquele que vê e daquilo ou daquele que é visto. A intersecção de suas metamorfoses consiste numa percepção (ibid:148). Essas trocas se dão

\footnotetext{
${ }^{3}$ A noção de corporeidade dos corpos foi sugerida alhures (LIMA, 2007:49) como superação da contradição entre o espaço corporal (relativo) marcado por uma flagrante empiricização e o espaço absoluto notadamente reflexível ou apriorístico. A corporeidade dos corpos consiste, em linhas
} 
no encontro com a diferença, com a alteridade, de modo que se assegure uma identidade no contraste com o outro, ou ao menos assegure um campo de presença isento de incompossibilidades sem, todavia, anular as contradições.

Nos trabalhos que antecederam sua repentina morte, Merleau-Ponty cunhou uma noção que precisa a inerência entre o corpo e o mundo: a carne é a imanência das coisas no corpo, o emblema concreto geral que os interligam ao mundo, o modo como estão inspiradas nele e inversamente. A carne é o quiasma que reúne as dimensões objetivas e fenomênicas do corpo numa mesma superfície de contato, estendendo ramificações entre o corpo e o mundo. "O quiasma liga como avesso e direito conjuntos antecipadamente unificados em vias de diferenciação" (MERLEAU-PONTY, 2005:236).

Por entender o mundo como um conceito dos mais abstratos, de vez que nada mais é do que um conjunto de virtualidades ou possibilidades, o substituiremos por um outro conceito não menos abstrato, porém passível de apreensão por meio de suas partes constitutivas. O que para Merleau-Ponty é o mundo ${ }^{4}$ será interpretado daqui por diante como espaço total, o que significa entendê-lo, em última instância, como élan geográfico da existência, o lócus em que se vivificam as relações, em tese, um meio de possibilidades para o qual a ordem dos sentidos e dos significados ainda não estão prontamente determinadas. Tomamos o mundo como o espaço geral de nossos significados, mas que sob certas circunstâncias nos comparece como o espaço objetivo de nossos sentidos de onde a carne compõe o seu preenchimento.

O ordenamento de nossas percepções supõe uma relação de reciprocidade em que corpo e espaço se implicam mutuamente. Para um indivíduo não haveria espaço se ele próprio não fosse um corpo no mundo, ou seja, ele é no espaço. "A espacialidade do corpo é o desdobramento de seu ser de corpo, a maneira pela qual ele se realiza como corpo" (MERLEAU-PONTY, 1999:206). Nesse sentido, toda experiência corporal é por definição e princípio uma experiência espacial.

Isto quer dizer que os mesmos princípios que ordenam e que emanam do corpo comparecem do mesmo modo ao espaço, não como leis causais e mecânicas, mas como leis reversíveis enquanto emanações do corpo que o associa às coisas e ao outro. "Pode-se dizer ao pé da letra que o espaço se sabe a si mesmo através do meu corpo" (MERLEAU-PONTY, 1975a:437). Esta frase demonstra como o espaço encorpora ${ }^{5}$, a partir de uma imanência com o corpo, propriedades que se convencionou atribuir a um sujeito do pensamento. Como um espaço "se sabe a si"

gerais, num meio relacional que aglutina variados corpos entrecruzando suas percepções, intencionalidades, afeç̧ôes, atos, realizações, enfim, suas diferenças em prol de um sentido de espaço sob a perspectiva da experiência corpórea.

${ }^{4} \mathrm{O}$ mundo para Merleau-Ponty (1999:576) é a "unidade primordial de todas as nossas experiências no horizonte de nossa vida e termo único de todos os nossos projetos".

${ }^{5} \mathrm{O}$ neologismo encorporar se justifica apenas para designar o sentido reverso da expressão incorporar, ou seja, ao invés de uma introjeção do mundo, o que se tem é uma exteriorização do cọpo nas coisas. 
sem consciência? Tal assertiva supõe admitir que corpo e espaço já não são entidades à parte, passaram a configurar um único ser, uma corporeidade dos corpos. Importa saber como o corpo real ${ }^{6}$ passa ao espaço, entrelaça-se com ele embaralhando seus limites, torna-se carne.

É nesse sentido que Silva (2000:7) destaca que "o que é geográfico está diante de nossa percepção e possui um significado dado pela particularidade e pela forma: aquilo que se apresenta como um momento de existência de uma configuração do espaço e pelo movimento diferenciado e múltiplo neste". Ele nos participa que a particularidade é um dado seminal para a diferença e a multiplicidade, e a forma figura como fundo espacial da existência. Sua particularidade nutre toda diferença.

Merleau-Ponty (1999:147) ensina que, em se tratando de espacialidade, o corpo próprio é o terceiro termo da estrutura figura e fundo. A figura designa o limite exterior das coisas, ou seja, a aparência que elas tomam tal como se revelam e sob a qual a identificamos. O fundo é um campo perceptivo total, um meio pronto a estabelecer relações, o espaço absoluto ou o próprio mundo como meio geral de nossas experiências de vida, independente de fixarmos um ou outro objeto no curso dos acontecimentos. Sendo a relação figura-fundo constitutiva de toda forma, como supõe Chauí (2002: 119), uma vez que o corpo é a resultante desta relação triádica podemos depreender que a forma consiste num corpo se realizando segundo uma dada experiência, dando-lhe conteúdo ao produzir um fundo com tantos outros corpos, constituindo um recorte do espaço na esteira constitutiva da totalidade. Para o positivismo o sentido de um corpo como estrato fisiológico é a forma positiva compondo uma unidade cujo valor sensorial é determinado por uma função no interior de um todo. Todavia, para Merleau-Ponty (2006:224) a forma deriva da experiência perceptiva: "a forma é pois não uma realidade física, mas um objeto da percepção". E é por isso que esse autor vai dizer que o conteúdo corporal em relação à forma é algo de opaco, de acidental e de ininteligível e não tão evidente como advogam a física, a biologia e a psicologia (MERLEAU-PONTY, 1999:147, 148). Da subjunção da figura e do fundo advêm formas distribuídas em acontecimentos locais que se determinam mutuamente. Essa imbricação entre figura, fundo e forma compõe o alicerce básico para uma fenomenologia perceptiva do espaço, todavia ainda incompleta. Faltar-lhe-ia, dentre outras coisas, o movimento.

O movimento do corpo é um dos seus modos de ser no tempo e no espaço ou, se preferir, uma de suas manifestações. O movimento é por definição particular, embora plural e diferenciado, perfazendo o jogo do uno e do múltiplo ao promover a distribuição e a localização dos corpos no espaço. Mais que isso, ele articula os corpos pelo cruzamento motor, convocando o espaço para protagonizar a cena e não somente para se prestar de palco. Através das capacidades proprioceptivas

\footnotetext{
${ }^{6} \mathrm{O}$ corpo real é o seu sentido biológico ou fisiológico, acepção que se convencionou entender como corpo físico ou também objetivo.
} 
dos músculos, dos tendões, o corpo informa sobre o movimento e a posição. $\mathrm{O}$ movimento do corpo deriva de uma inclinação intencional em direção aos objetos espaciais, mobilizando outros corpos sobre os quais se projeta, não se limitando, portanto, à antípoda repouso e movimento tal qual prescreve a Física. Tudo está fadado ao movimento; mesmo o aparentemente estático tende a avançar no tempo e no espaço. As células envelhecem, os objetos se deterioram e o planeta gira sob a ação de uma força gravitacional ininterrupta. O movimento conduz à medida do tempo, mas não é ele propriamente o tempo, assim como a medida quântica do espaço é a extensão sem que aquele se reduza a esta. Mas a distância é também medida do tempo assim como o movimento pode aferir um espaço, denotando a congruência entre essas categorias (tempo e espaço).

Entretanto, movimento, distância e imobilidade nada significariam se o corpo não fosse a sua mediatriz. É nesse sentido que Merleau-Ponty (2005:212) vai dizer que em princípio toda percepção é movimento. Dois objetos não podem determinar a distância entre si, ainda que se faça valer o movimento (ação), senão pela intervenção de um medidor (o corpo). Assim, um passo pode ser a unidade corporal de tempo e espaço a designar as distâncias e infringir a pausa e a tensão ao promover o movimento (TUAN, 1983:132). Michel de Certeau (2003:177) acrescenta que o ato de caminhar tem uma tríplice função enunciativa: "é um processo de apropriação topográfica pelo pedestre; é uma realização espacial do lugar; enfim, implica relações entre posições diferenciadas, ou seja, 'contratos' pragmáticos sob a forma de movimentos". O caminhar aponta para uma manifestação motora dos corpos, em outras palavras, seu movimento produz espaço instaurando relações por um ato enunciativo como manifestação de uma linguagem.

"Um órgão móvel dos sentidos (o olho, a mão) já é uma linguagem porque é uma interrogação (movimento) e uma resposta (percepção como Erfüllung ${ }^{7}$ de um projeto), [assim como] falar e compreender" (MERLEAU-PONTY, 2000:341). O espaço só o é como tal se existirmos num corpo e se o dotamos de sentido, se nos comunicamos constantemente com e por ele. A fala secreta um sentido, ela é a maneira como esse sentido se apresenta. "A linguagem tem um papel fundamental na vida do homem por ser a forma pela qual se identifica e reconhece a objetividade em seu derredor, através dos nomes já dados" (SANTOS, 2002:67). A linguagem, na medida que consiste em signos enunciativos, dá corpo ao pensamento fazendo a mediação com os objetos e com outrem. A propósito da linguagem em termos merleau-pontianos, Chauí (2002:17) vai discorrer:

Quando alguém fala, põe em movimento todo o sistema de diferenças que constituem a lingua e das quais depende o sentido proferido; alude a significações passadas e vindouras numa constelação significativa essencial para o sentido presente; relaciona-se com outrem, de cuja escuta

\footnotetext{
${ }^{7}$ Realização.
} 
e resposta dependem seu próprio investimento como sujeito falante; corporifica seu pensamento à medida que vai dizendo.

A linguagem é o meio pelo qual operamos o liame entre os corpos. Ela é o sistema de representações e relações simbólicas que nós produzimos como síntese da pluralidade de nossas experiências, dotando assim o corpo de um complexo de fenômenos expressivos. É por meio da linguagem que compreendemos o outro, que experimentamos um estado de co-presença. A cadeia lingüística se constrói na fala por palavras diferenciais. A fala permite-nos vivenciar um campo de presença comum, pensar segundo o outro, compartilhar. Mas, não compreendemos o outro por um ato de interpretação intelectual prévio, pois o pensamento e a palavra se constituem simultaneamente. Não é equivocada a expressão "estou pensando alto". Mesmo quando pensamos em silêncio, pensamos por meio de palavras. "O ato fundador é dar um nome e, por isso, é a partir do nome que produzimos o pensamento e não o contrário" (SANTOS, 2002:67). A palavra é a metáfora primordial, pois realiza a condução de um objeto percebido à imagem (palavra) formada mentalmente. A palavra é a idéia encarnada. Pela nominação dos objetos, o dotamos de um sentido ou de evidências próprias que é a resultante de uma intencionalidade.

\section{A impossibilidade de uma reduçāo completa}

Uma das propostas centrais da fenomenologia é a da intencionalidade, segundo a qual toda consciência é consciência de... Ou se existe algo, temos a consciência deste algo como objeto pela sua apreensão perceptiva ou mesmo intelectual. Assim, simultaneamente, tomamos consciência de nós mesmos como sujeito. A intencionalidade evoca sempre o seu caráter relacional interligando seus termos por meio da consciência. Logo, ter consciência de algo é se posicionar no domínio das intencionalidades. É convocar a unidade dos sentidos confundindo a relação pela indefinição da condição de sujeito em face de um objeto, embora tais qualidades sejam marcadas por uma reciprocidade entre propriedades diferenciais que designam a cada qual seu papel. A intencionalidade resultante dessas trocas, ou antes, a intencionalidade que as acionam, é que designa o caráter subjetivo e objetivo do corpo. No entanto, a intencionalidade (assim como a consciência, a percepção, a sensação, a reflexão) não consiste numa qualidade particular do sujeito ou do objeto; mas nada mais é que a resultante da troca conjunta de sentidos e significados. Sujeito e objeto são emanações do corpo que afloram no confronto com a alteridade.

Para Husserl (1989:48) a intencionalidade é consciência de alguma coisa. "A palavra intencionalidade significa apenas que essa particularidade intrínseca e geral que a consciência tem de ser consciência de qualquer coisa, de trazer, em sua qualidade de cogito, seu cogitatum em si próprio" (ibid:48). A intencionalidade precede qualquer predicação, requerendo uma suspensão do juízo, ou seja, um 
pré-juízo. "Ou, mais exatamente: o ato de julgar [em si] constitui uma "intenção", (ibid:21). A fenomenologia husserliana supõe uma averiguação prévia de toda préconcepção de pensamento ou de realidade. Requer uma epochê, isto é, um retorno à própria coisa, o que este autor vai designar de redução ou descrição eidética, segundo a qual cada acontecimento, cada dado particular, remete sua significação à situação ontológica originária, passando da atitude natural à atitude transcendental.

É apenas no quadro da fenomenologia e relacionando as diferença do ser dos objetos que se constituem com as relaçôes essenciais das multiplicidades constituintes que lhe correspondem, que tais diferenças podem ser mantidas fora de todo embaralhamento (unverwirrt) numa separação que oferece uma certeza absoluta (in absolut sicherer Sonderung) liberadas de todos os mal-entendidos que têm suas fontes em suas mudanças de atitudes involuntárias e que, falta de reflexão pura, permanecem despercebidas de nós. Somente retornando à consciência absoluta e à totalidade das relações de essência que podemos seguir nela, que nós poderemos enfim compreender segundo o seu sentido as relações de dependência dos objetos que correspondem a uma e à outras atitudes, e suas recíprocas relações e essências (HUSSERL, ${ }^{8}$ apud. MERLEAUPONTY, 1975a:448).

A redução eidética em Husserl está fundamentada, portanto, numa suspensão momentânea de nossa representação de mundo, que ao se naturalizar impossibilita a compreensão da relação de dependência entre sujeito e objeto considerados em sua essência, passando pois despercebida, daí a necessidade de se abster para melhor interpretá-la. Husserl pauta-se numa metafísica que tem a essência ${ }^{9}$ como

\section{${ }^{8}$ HUSSERL, Edmund. Ideem $I I: 180$}

9 "As essências são este sentido intrínseco, estas necessidades de princípio, seja qual for a realidade em que se misturam e se confundem (sem que, aliás, suas implicações deixem de fazer-se valer), único ser legítimo ou autêntico que tem a pretensão e direito a ser, e que é afirmativo por si próprio. já que é o sistema de tudo o que é possível para o olhar de um espectador puro, traçado ou desenhado daquilo que, em todos os níveis, é alguma coisa - alguma coisa em geral, ou alguma coisa material, ou alguma coisa espiritual, ou alguma coisa viva" (MERLEAU-PONTY, 2005:107, 108).

10 "É o que Husserl punha francamente a nu quando dizia que toda redução transcendental é também redução eidética, isto é, todo esforço para compreender de dentro e a partir das fontes o espetáculo do mundo exige que nos separemos do desenrolar efetivo de nossas percepções e de nossa percepção do mundo, que nos contentemos com sua essência, que nos deixemos de confundir com o fluxo concreto de nossa vida para retraçarmos o andamento de conjunto e as articulações principais do mundo sobre o qual ela se abre" (MERLEAU-PONTY, 2005:53).

"Respectivamente, o aspecto objetivo e subjetivo da vivência, ou seja, de um lado o percebido, o imaginado e o pensado e de outro a percepção, a imaginação e o pensamento.

${ }^{12}$ Em um conhecido artigo, O Filósofo e sua Sombra, Merleau-Ponty (1975a:430, 431) precisa as análises que levaram Husserl ao impasse da constituição transcendental.

13 "Quando Husserl termina sua vida, há um impensado de Husserl, que é muito seu e que, no 
uma natureza única constituindo o cerne do ser, o que vai restringir tanto a descrição eidética como a consciência às raias do idealismo transcendental. ${ }^{10}$ Atrelado à separação entre noema e noesis ${ }^{11}$ o ser resplandece isolado como correlato dessa consciência transcendental. Husserl ignora o problema da alteridade, da intersubjetividade e as contradições que elas impõe à consciência, de vez que a consciência transcendental não pode constituir outra consciência, pois ela parte do pressuposto metafísico que toda realidade concebível subsiste apenas numa experiência externa indubitável subentendida por um sujeito cognoscente.

Em Merleau-Ponty a noção de intencionalidade funda um novo modo de interpretar o corpo, embora os últimos trabalhos deixem transparecer o abandono da consciência e da intencionalidade em suas análises, quando muito estariam associados ao criticismo transcendental (MERLEAU-PONTY, 2005:212, 218). Não obstante, ele se inspiraria na epochê husserliana para por fim ultrapassá-la. E embora Husserl tenha considerado a fenomenologia uma continuidade dos clássicos (Descartes, Espinosa, Leibniz, Kant), Merleau-Ponty encontra na "sombra de Husserl" 12 a maneira de superá-lo. Interessando-se mais pela gênese do sentido do último Husserl, o que considera o "impensado de Husserl", ${ }^{13}$ Merleau-Ponty (1999:10) avalia que "o maior ensinamento da redução eidética é a impossibilidade de uma redução completa". Ele adota as teses husserlianas como ponto de partida para situar a realização perceptiva do corpo como princípio estruturante do espaço a fim de superar a antinomia entre a sensação enquanto estado de consciência e a sensação enquanto consciência de um estado, entre a consciência em-si como posição e a consciência para-si como negação, restaurando-as como textura da experiência.

Atrelando a consciência ao corpo Merleau-Ponty vai sugerir uma consciência perceptiva, assim a consciência deixa de lado o campo transcendental e se torna o campo da experiência. A percepção revela a impossibilidade de uma redução completa e, portanto, de uma consciência plena, o que permite um liame entre a experiência e a representação. A reflexão, também incompleta, é deslocada da consciência para o corpo, assumindo assim uma corporeidade reflexionante. Em lugar de uma consciência estanque do mundo, a priori de toda experiência, a consciência perceptiva está enraizada na e pela experiência. Poder-se-ia dizer que a sensibilidade ou sensação é incompleta e insuficiente sem o pensamento e inversamente. Sem que sejam opostos entre si, a sensação é o outro da reflexão, como o é de tal modo entre si a linguagem, o algoritmo, o cálculo, a nota musical: diferentes e não antagônicos, todavia complementares.

entanto, abre para uma outra coisa" (MERLEAU-PONTY, 1975a:431). "Essas análises do Husserl tardio [...] explicitam a 'tese do mundo' antes de toda tese e de toda teoria, aquém das objetivaçōes do conhecimento, tese de que Husserl sempre falou e que, para ele, tornou-se nosso recurso para o impasse produzido no saber ocidental por aquelas objetivações" (ibid:450). 
Assim, nenhuma experiência decorre impunemente sem que sobrevenha um sentido e um significado. O significado consiste numa síntese intelectual, ele é o conceito em termos estritos; enquanto o sentido se refere à apreensão sensível imediata de mundo, ele instaura a realização do corpo como tal e como espaço. O significado de um sentido é a sua redução a uma síntese intelectual. Mas, para que o sentido se torne um significado ou conceito mediante uma síntese intelectual é preciso a reincidência de uma série de experiências regulares e retroativas de modo a permitir um conjunto de representações que validará o significado. Portanto, não há uma prevalência do significado sobre o sentido e o mesmo é válido se invertermos a ordem dos termos. Se por outro lado é possível alçá-los a resultados mais complexos de seus rebatimentos, essa possibilidade se daria não por uma síntese formal que os limitariam a uma idéia ou conceito, mas sim pela pluralização que suas diferenças autorizam, uma linguagem empírica e simbólica empregada no ato da relação com os objetos e que a nós (sujeitos) retorna realimentando nosso ser de corpo, o modo como ele se realiza em ato. $O$ enlace que unifica sensibilidade e pensamento, parte do mesmo princípio da união entre corpo e alma e subentende uma indissociabilidade entre corpo e espaço. A cor, o ruído, a textura, o odor, o gosto são qualidades sensíveis na medida que nos relacionamos e damos sentido aos objetos. Analogamente, o comprimento, a altura, o volume, a densidade são qualidades abstratas advindas da reflexão à proporção que interrogamos o significado dos objetos. Em ambos os casos os objetos restituirão um sentido que resignifica o sujeito, todavia, conformam um mesmo ato, discerníveis apenas por pertencerem a dimensões corporais distintas, porém indissociáveis.

A descrição eidética de qual Merleau-Ponty lançaria mão não cimenta a essência como princípio elementar, mas, todavia, prescreve a percepção como abertura primeira de mundo, como horizonte inaugural da existência. A redução de um fenômeno à sua essência é quimérica, pois requer um sobrevôo contemplativo sem nenhum background da experiência. Nesse sentido, a essência é factualmente inacessível. É por isso que Merleau-Ponty $(2005: 112,117,120)$ vai pretender redefinir a essência, não como um "retorno ao imediato, uma fusão efetiva com o existente ou como um segredo perdido a reencontrar", mas como "aderência e reversibilidade de um ao outro", como superfície da experiência. Ante a primazia de uma ontologia das essências, ele propõe um recomeço: "rejeitar os instrumentos adotados pela reflexão e pela intuição, instalar-se num local onde essas ainda não se distinguem, em experiências que ainda não foram 'trabalhadas', que nos ofereçam concomitante e confusamente o 'sujeito' e o 'objeto', a existência e a essência, e lhe dão portanto os meios de defini-los" (ibid:127). A partir da superação heideggeriana da metafísica, a essência perde o seu caráter de substância suprasensível e passa a significar origem, procedência de onde algo nasce ou provém; enquanto a existência ultrapassa o seu caráter de substância sensível, singular, para significar superfície de possibilidade do ser (MICHELLAZZO, 
2003:117). Abandonando as teses husserlianas, Merleau-Ponty se enveredaria pelo existencialismo de Heidegger a fim de apreender o corpo como solo originário da experiência, como enraizamento espacial na existência.

\section{Esboço para uma teoria crítica do sujeito em Geografia}

Ao deslocar a reflexão da consciência para o corpo Merleau-Ponty supõe superar o estrabismo cartesiano que inaugura a dicotomia sujeito-objeto, consciência-coisa, res cogitans-res extensa. O racionalismo cartesiano nos persuadiu a pensar o objeto com um fim em si mesmo e a consciência como algo dado. Com a consciência perceptiva, todavia, não pensamos o objeto puro e simplesmente: interagimos com esse corpo que nos revela um espaço. Ou seja, se estivesse voltado exclusivamente para consigo, o corpo não poderia ter consciência nem mesmo de si, mas, voltando-se para o espaço, ele expande seus horizontes agregando múltiplas experiências. Desse modo, o corpo adquire consciência de si mesmo mediante a percepção do espaço.

A realização do corpo implica o agenciamento das qualidades perceptivas da consciência, o que pressupõe a indissociabilidade entre faculdades sensíveis e intelectuais. Admitir a experiência intelectual fora do corpo seria incorrer no mesmo equívoco cartesiano. Privilegiar a experiência sensível às expensas do pensamento seria como ratificar o empirismo. A consciência perceptiva evoca num ato unívoco sensibilidade e reflexão. O percebido e o reflexivo configuram um mesmo gesto, de modo que são emanações sempre inacabadas que se entrelaçam entre si por meio das qualidades reversíveis que lhes são inerentes. Por isso o corpo é um instrumento cognoscente, um corpo reflexionante. Deslocada do domínio da consciência pura, a reflexão é posta no sensível instaurando uma consciência perceptiva, invalidando assim toda reflexão completa e irrestrita. "O corpo reflexionante não vem desalojar o 'logocentrismo ocidental', mas vem modificar radicalmente a própria idéia de reflexão" (CHAUí, 2002:141).

A consciência perceptiva supõe sempre um objeto identificável, demandando sempre um elo entre sujeito e objeto, entre corpo e espaço. Ela se põe a par de um conjunto de relações relativamente transparentes, de um espaço, de uma história, dos objetos percebidos em suas singularidades e generalidades para extrair suas particularidades. Não se trata, contudo, de pura relação entre sujeito e objeto, porquanto que um intervém no outro. Quardo interagimos com um objeto, emprestando-lhe um significado, ele automaticamente nos restitui um sentido. Os objetos são como espelhos refletindo imagens dos sujeitos, no sentido de que "ver implica a possibilidade de se ver" (MERLEAU-PONTY, 2000:439). O objeto restitui sentido ao sujeito através de sensações como uma dor, um sabor, imagens que podem incitar o medo, a cólera, a concupiscência, ou seja, por impressões que demandam intencionalidades e atitudes. 
Refletimo-nos nas coisas ao percebê-las. O reconhecimento das coisas não se funda no reconhecimento de alguma lei ou categoria absoluta, mas na experiência de uma presença corporal. "O corpo é nada mais, nada menos, a condição de possibilidade da coisa" (MERLEAU-PONTY, 1975a:444). Neste sentido, as posições do corpo e da coisa são invertidas: esta é descrita como algo vivo, animado (um corpo), aquele como algo que ocupa lugar no espaço (uma coisa). Essa implicação mútua entre um corpo-coisa e uma coisa-corpo constitui uma unidade sui generis: o corpo reflexionante, carne, inserindo ambos no mesmo tecido intencional (ibid:436). Desse modo, não é o sujeito reflexivo que efetua a síntese de um plano escalar do espaço, mas é o corpo que agrupa a sua pluralidade de horizontes se expandindo para além de sua dimensão biológica ou fisiológica.

Todo pensamento e percepção de um objeto é ao mesmo tempo consciência de si, de que se é um corpo no espaço como expressão material de todas as ações. Por isso o sujeito não se reduz à consciência que tem do objeto. Mesmo porque se pode passar de sujeito a objeto e deste àquele indefinidamente. Quando nos tocamos com a própria mão, a mão tocada é, com efeito, um objeto apreensível, de modo que a mão que toca é para nós um emblema do sujeito; conquanto que as respectivas funções se invertam, a mão que toca se torna a tocada pela restituição de um sentido complexificando toda a relação. "Assim, porque eu me toco tocando, meu corpo realiza "uma espécie de reflexão"” (MERLEAU-PONTY, 1975a: 437).

O ato de ver o corpo como objeto ou como sujeito, vai dizer Sartre (1997:448), é um dado absolutamente contingente. Essa possibilidade só é admissível se posicionando do ponto de vista do outro. Negar a si mesmo como sujeito para se reapreender como objeto requer fazê-lo do ponto de vista do outro, aceitando-lhe como sujeito e se alienando enquanto tal. É nesse sentido que Sartre (ibid:441, 451) vai elencar três dimensões ontológicas do corpo: 1. o corpo como "ser-parasi" é o corpo se realizando como sujeito em face do outro (objeto), trata-se de um ser que responde a si mesmo ("eu existo", "meu corpo"), ele pertence "às estruturas da consciência não-tética de si mesmo" (ibid:445), dentro dessa ótica o corpo é sempre transcendido; 2. o corpo como "ser-para-outro" supõe que o outro se revela como sujeito tomando consciência deste corpo como objeto; e 3. o corpo como "ser-em-si em presença do outro" é o corpo tomando consciência de si pelo ponto de vista do outro e, portanto, alienando-se como sujeito ao se reconhecer objeto. É neste último sentido que esse autor vai dizer "eu existo para mim como conhecido pelo outro em forma de corpo" (ibid:451).

A consciência não é, pois, uma propriedade do sujeito, ela não é uma propriedade interior e subjetiva como supõe o cogito cartesiano, mas sim um estado (de consciência) que compreende percepções sensoriais, intelectuais e emotivas instituídas numa relação entre o eu e o objeto. Não está encerrada no cerne da alma ou da razão humana, validando por dentro o que percebe de fora pelas faculdades sensíveis e intelectuais. A consciência não depende, portanto, de uma 
operação mental independente do espaço. Ela escapa ao se lançar em direção aos objetos, sem, todavia, se confundir com eles. Sem o objeto a consciência não passaria de mera abstração. "Uma consciência que fosse consciência de nada seria um nada absoluto", escreve Sartre (ibid:758). Mas, a consciência também não reside nos objetos, como se fosse expressão de suas funcionalidades. Não é o objeto a causa determinante do ato intencional. Aliás, se nos prendêssemos a relações causais não chegaríamos a consenso algum. Em termos sartrianos, a consciência não está determinada pelos sujeitos e tampouco pelos objetos, senão por ela mesma: "uma mesa não está na consciência nem a título de representação. Uma mesa está no espaço, junto à janela, etc." (ibid:22).

Sartre (ibid:33) vai dizer que a consciência nadifica tudo com o que se relaciona, pois ela se lança sobre os objetos sem se objetificar, sem trazê-los para dentro de si, sem assumi-los por causa ou direito e, portanto, sem se prender à sua essência, recusando-a, ainda que afirmando a sua existência, fazendo-se existir no mesmo ato de recusa de um ser que não é ela mesma (a consciência). Para Sartre o ser é o em-si, substância, resistente, opaco e viscoso, objetividade nua e bruta; a consciência é o para-si, insubstancial, não é alma, psique ou substância imaterial, mas pura atividade e espontaneidade, subjetividade plena (CHALÍ, 2002:272). "Ser é possuir essência, ser determinado, realidade plena, acabada, ao passo que existir é não ser determinado, não possuir essência, ser nada, pura possibilidade, liberdade" (COÊLHO, 2003:88). Separada de tudo que pudesse determiná-la, de todo tipo de causalidade, posto que o nada se torna um pressuposto da existência, a consciência é pura indeterminação, é consciência de si como liberdade. "Pura existência (sem essência), indeterminação radical, projeto, a consciência é liberdade que não consegue determinar-se" (ibid:90).

Entretanto, Merleau-Ponty (2005:233) acusa o nada sartriano de dar prosseguimento ao projeto intelectualista iniciado por Descartes e desdobrado por Kant, Hegel e Husserl, ${ }^{14}$ qualificando-o como uma "filosofia da "práxis individual"". "A idéia de um nada absoluto é contraditória. Não existe vazio no mundo, todo pensamento do vazio é pensamento de uma certa plenitude" (MERLEAU-PONTY, 2000:109). O ponto de chegada de Sartre, a união do ser pela sua negatividade, é o ponto de partida de Merleau-Ponty (2005:216) segundo o próprio, ou seja, ele não vai atrelar a existência à negação do ser e da essência, mas identificá-los como pregnantes da existência por meio da experiência. Nesses termos, ser e essência exprimem-se no terreno da experiência, porquanto que a experiência seja expressão corpórea da existência, logo, "a essência sendo essência 'de alguma coisa', só pode ter certeza de seu conteúdo e de sua adequação ou verdade supondo

\footnotetext{
${ }^{14}$ O Nada sartriano é a nova versão da consciência de si reflexiva de Descartes depois de reformulada por Kant, Hegel e Husserl, portanto, soberana, fundadora, constituidora do sentido do ser (CHAUí, 2002:273). "É graças a essa intuição do ser como plenitude absoluta e absoluta positividade, graças a uma visão do nada purificado de tudo o que nele metemos de ser que Sartre pensa explicar o nosso
} 
a existência daquilo que é essência" (CHAUÍ, 2002:93). A existência disponibiliza um campo de possibilidades para que a experiência espose uma escolha dentre muitas possíveis revelando assim uma particularidade do ser. Experimentamos as coisas pela reversibilidade que a experiência impõe, de modo que o inteligível se reverta no sensível de direito sem o sê-lo de fato, reunindo assim o sujeito e o objeto, a cultura e a natureza, a liberdade e a necessidade e assim por diante, cada qual se realizando no outro sem, contudo, se anularem ou se sobreporem.

As dimensões do visível e do invisível são particularmente fecundas para a discussão em tela. Através delas se pode afirmar a identidade sob a pluralidade de perspectivas a que está submetida. O visível não é necessariamente o sensível, assim como o pensamento não expressa de todo o invisível. Merleau-Ponty (2005:232) adverte que o invisível não é um não-visível: "não sendo o visível um positivo objetivo, o invisivel não pode ser uma negação no sentido lógico". O invisível não significa estritamente uma ausência, mas é antes diferença e como tal não consiste em mera oposição. É também possibilidade, ou melhor, o possivelmente visível. O visível pode ser qualquer coisa: uma sensação, uma idéia, um ato voluntário ou involuntário, um desejo; desde que o invisível marque a variável diferencial que implique em interações e efeitos recíprocos que resultem na validação de um campo de presença que estimule a promiscuidade entre ser e mundo. $\mathrm{O}$ invisível é, pois, presença diferencial, é complementaridade, não é negação por exclusão, mas sim por pertença da posição. Essa dimensão do ser, portanto, não se afirma pela ausência do par aparentemente antinômico, mas pelo entrelaçamento recíproco, sem que, no entanto, se confundam, sem que se convertam uns nos outros e sem sobreposição. O que permite que o visível compreenda um odor, um paladar, um pensar ou experimentar múltiplos horizontes do invisível sem que se perca o seu emblema de visível e vice-versa. Desse modo, as coisas não são objetos externos que se converteriam em puras essências, tão pouco os sujeitos o são de modo tal em relação à consciência. Mas a consciência também não consiste num nada, e sim em mais uma emanação do corpo que advém do encontro com a alteridade. É a diferença entre os incompossíveis que os convertem em compossíveis permitindo se retroalimentarem, se reconhecerem como unidade na multiplicidade.

Nossa percepção dos objetos remete a uma espacialidade em que a experiência do corpo nos ensina a enraizar o espaço na existência. Em termos espaciais a consciência permite, grosso modo, a localização e distribuição das coisas à medida que posiciona a nós mesmos no espaço. Fitamos um objeto e o tomamos como um corpo no espaço ao mesmo tempo em que nos identificamos como um

acesso primordial às coisas. sempre subentendido nas filosofias reflexionantes e sempre compreendido no realismo como uma ação impensável das coisas sobre nós. A partir do momento que me concebo como negatividade e o mundo como positividade, não há mais interação, caminho eu próprio diante de um mundo maciço; entre ele e eu não há encontro nem ficção, porquanto ele é o ser e eu nada sou" (MERLEAU-PONTY, 2005:59). 
corpo neste espaço. Um som que ressoa fora do corpo é o mesmo que, tornado objeto, se funde no mesmo ato com o sujeito restaurando todo o corpo. Quando tocamos um objeto e o impregnamos de um significado, nos contaminamos igualmente com a restituição de um sentido. Operamos concomitantemente um duplo horizonte: o objetificamos por nos reconhecermos sujeitos, embora por vezes nos rendamos à sua facticidade; o individualizamos para distingui-lo dos demais, mas somos atraídos por sua capacidade sensível; o nominamos a fim de diferenciálo de tantos entes nominados, inclusive nós mesmos; o localizamos para distribuí-lo admitindo sua funcionalidade como engrenagem de um mundo do qual fazemos parte. Deduzimos, pois, o corpo de uma relação entre objetos para situá-lo como sujeito da percepção, logo, sujeito da ação.

O corpo compactua um sistema de objetos, que passa a ser seu elo interativo com outros corpos. Sartre (1997:410) vai dizer que fazemos parte do mundo pela utensilidade do corpo, isto é, a capacidade instrumental que o integra aos objetos e esses a outros tantos. Temos, pois, uma intencionalidade instrumental sobre os objetos. Sempre com vistas a atingir um fim, dotamo-lo de uma funcionalidade. "A função é a significação do objeto: é ela que lhe dá vida" (MOLES, 1981:170). Assim, o corpo se estende sobre todos os objetos que o cerca, confirmando sua disposição no espaço pelas indicações laterais dos "objetos-utensílios". Podemos, pois, reiterar o olhar sobre todos os demais objetos que o circunda e o identifica sob múltiplas perspectivas, de maneira que o objeto não esteja isolado no espaço. mas partilhando um conjunto de sistemas de objetos associado a um complexo de sistemas de ações (SANTOS, 2002:62, 63). Logo, a instrumentalidade do corpo assume um papel decisivo em meio a essa co-presença: os objetos indicam, por meio de suas disposições laterais, a perspectiva e a disposição de todos os outros corpos, todos conectados por um princípio complementar de reversibilidade que não exclui a contradição.

Da experiência da visualização do cubo aludida por Merleau-Ponty (2005:190, $191 ; 2006: 290$ ), interessa-nos apenas o quanto ela pode elucidar um campo de copresença. Um sujeito pode ver apenas três das seis faces de um cubo ao mesmo tempo. Temos, pois, uma dada perspectiva do objeto, dentre outras possíveis que são latências de nossas capacidades reflexivas e representacionais, como é o caso do significado geométrico das seis partes idênticas de um cubo. Mas, se por acaso pudéssemos considerar outras percepções, isto é, se dois ou mais sujeitos se postassem diante de um cubo, ainda que cada um por si só continue visualizando apenas três lados, não seriam todavia os mesmos lados que são sentidos por eles. Tais perspectivas preenchem umas às outras a percepção lacunar que recai sobre cada indivíduo desde que partilhem entre si a experiência, desde que a distribuição do outro no espaço referencie a localização de cada um deles, apresentando-se assim ao espectador como uma multiplicidade de perfis, como um meio intersubjetivo, de modo que até mesmo suas especulações e representações geométricas sobre 
as faces escondidas do cubo se tornem perfis autorizando permutar significados e reificar sentidos, pois, o que para um espectador é sentido evidente posto que apreendido em meio a facticidade do campo retiniano, para o outro é significado suposto, uma vez que lançado à aleatoriedade da hipótese. A imbricação com o outro se dá através de um sistema de perspectivas diferenciadas reversíveis; em todo caso o outro e a coisa compartilham suas diferenças.

Quando essas múltiplas perspectivas se entrecruzam; o sentido de um sujeito para com um objeto atrelado ao significado do outro para com o mesmo objeto e tantos outros mais que por seus caracteres reversíveis se nutrem de sentidos e significados alheios, somos arrastados para uma coexistência que funda o fenômeno da corporeidade dos corpos. São os objetos, vai escrever Moles (1981:14), "que servem de mediadores entre as situações e os atos assumindo uma função". O objeto é o mediador social (ibid:16). O objeto interliga, assim, um indivíduo ao outro e este a um terceiro, comprovando como o espaço é pregnante do corpo. Claro, levando em consideração que outro corpo, via de regra, é também objeto para quem em si é sujeito. Essa ubiqüidade do sujeito e do objeto no corpo, sua intermitente e indefinida troca de papéis, é que permite afirmá-lo como espaço, de modo que não haveria espaço se não houvesse corpos e vice-versa. Pelo fato das percepções serem extensivas umas às outras é que o corpo tem por princípio ser extensivo (via objetos) a todos os outros corpos, mas aí o corpo não mais se limitaria como uma coisa extensa no sentido que a tradição cartesiana lhe imputou, todavia, se manifestaria em meio a uma corporeidade dos corpos.

Assim como a percepção visual que temos do objeto é uma sobreposição de duas imagens capturadas por nosso aparelho retiniano e todavia a imagem que se nos apresenta é una, ou assim como é maior a certeza de possuir esse objeto tateando-o com as duas mãos ao invés de fazê-lo com apenas uma, assim é também a dedução que dele temos ao cruzar o seu sentido com o significado conjeturado a partir de nossas representações, que não são qualidades implícitas do sujeito mas, todavia, valores que eclodem do encontro com o objeto. Um esboço ainda incipiente do espaço supõe comparar as limitações perceptivas individuais que se têm desse objeto com as também limitadas percepções que o outro possui deste mesmo objeto, que variam conforme a experiência individual de cada um. Partilhamos sensibilidades e pensamentos porque eles são incompletos e se materializam nas ações e nos objetivos e não porque podemos sentir e pensar o pensamento do outro tal como ele mesmo pensa e sente. Cruzamos assim nossas representações, nossa consciência perceptiva e nossas intencionalidades através de objetivos comuns e mesmo discordantes com o outro. A tessitura carnal do corpo com as coisas se atualiza quando o outro presentifica sua configuração perceptiva com a nossa fazendo da corporeidade uma prova do ser (MERLEAU-PONTY, 1975a:440). Ampliemos, pois, essa evidência elementar para uma escala em que um campo intersubjetivo compreenda uma considerável variedade de corpos e coisas. Teríamos um protótipo 
estrutural que acrescentado do devenir histórico e de toda sorte de relações sociais nos suscitaria um espaço geográfico.

Eis a descrição eidética da qual Merleau-Ponty se ocupou em suas obras iniciais. Todavia, ela é sempre incompleta. Tal constituição obviamente não ocorre por etapas e tampouco por efeitos causais, e se o fazemos é por mero efeito didático. Seja como for, é também a insuficiência e a incompletude da reflexão, dos sentidos, das experiências, dos atos, dos objetivos e das próprias coisas que possibilitam uma simultaneidade em que os corpos se encaixam e se realizam como espaço.

\section{Uma perspectiva geográfica: o espaço percebido como paisagem}

O subtítulo acima possui dupla enunciação. Daí porque a expressão "percebido" se encontra grifada, pois é dela que deriva a dubiedade. De uma parte, ela permite entrever como a paisagem pode ser compreendida como um recorte do espaço. E de outra, supõe uma comparação entre a paisagem e um espaço percebido subentendido como espaço abarcado pela percepção, que também estamos chamando de espaço corporal. É para esta última acepção que nos deteremos mais, sem contudo excluir a primeira como possibilidade sempre recorrente.

Podemos deduzir uma forma por uma cor, um gesto, um som, um odor, um sabor; ou ainda uma lembrança ou idéia por um odor ou sabor, sendo igualmente válida qualquer aleatoriedade de combinação entre essas partes. E é no entrelaçamento dessas afeç̧ões somáticas que nos tornamos co-participes de um espaço que não é nem a redução da forma ao conteúdo, nem a subordinação do conteúdo a uma forma determinante, mas um espaço pronto a nos ensinar sobre o mundo e sobre nós mesmos ao conciliarmos essas nuanças. Um ambiente em que o som ressoa por todos os recônditos, ao passo de um dado relance do espaço capturado por um odor que lhe impregna de sentido, assim como uma forma que nos convence (ou nos convida a outro termo) por ser palpável, ao largo de uma paisagem avistada a se fundir em cores e texturas na linha do horizonte por estimular nossas emoções e nos cooptar para sua história: todos esses exemplos consistem num espaço corporal ou percebido. O espaço demarcado pelo corpo próprio, o espaço percebido, é o recorte do espaço abarcado pela percepção. Ele é um campo perceptivo, o meio de nossa experienciação sensório-motor-comunicativa, não possuindo, portanto, delimitações rígidas e precisas.

Mas, no que concerne ao concurso da experiência perceptível na conformação de um segmento do espaço, o que diferencia uma paisagem de um espaço percebido? Não obrigatoriamente haveríamos que distinguí-los como termos excludentes. Paisagem e espaço percebido ou corporal, possuem uma semelhança flagrante no que diz respeito ao aspecto comum da participação sensível em seus 
processos constitutivos. Porém, há um componente diferenciador. Não somente a paisagem como os demais recortes espaciais têm pontos de contato com o espaço percebido, de vez que a experiência corporal atravessa todo tipo de relação, pois não haveria relação (ou antes, ação) se não houvesse a presença de um sujeito para partilhá-la com os objetos. E é exatamente o papel do sujeito (e do objeto, por analogia) o fator mais substancial da distinção entre paisagem e espaço percebido.

São mesmo múltiplas as maneiras como os sujeitos que compõem uma paisagem podem comparecer a ela. Contudo, o espectador não é necessariamente um elemento da paisagem, ele está fora. E a paisagem já não é a mesma para os demais sujeitos que a compõe e para o sujeito-observador (que qualificaria os primeiros como meros objetos). Um espaço percebido, por seu turno, supõe o próprio sujeito se engajando e vivenciando um fragmento do espaço, entrelaçandose com ele. Sujeito que encarnado num corpo se porta de forma irremediável como termo integrante do espaço, não se limitando, pois, a um mero espectador, um cogitatum. Ele não contempla a paisagem como um fundo, mas vivencia a paisagem de seu interior, se perde em seus gradientes num pulular de experiências.

Levada a efeito como que num acontecer progressivo, se é que se pode tratar nesses termos, a experiência espacial fundante decorre de uma relação que nos suscita o recorte da paisagem, de sorte que essa relação acate a chancela de uma experiência perceptível. O discurso geográfico da relação homem-meio, transfigurada na relação sociedade-espaço, é mediada pela paisagem em suas variadas perspectivas: relação metabólica entre homem e natureza; gêneros de vida; meio geográfico; experiência sensível e outros. Moreira (2002:22) destaca que "a paisagem é o plano da percepção sensível pelo qual se inicia e se fecha todo processo analítico em geografia", ela seria assim, continuando seu raciocínio, "o nível do aparecimento fenomênico das relações de domínio do território nascidas dos recortes do espaço" (ibid:22). À medida que as relações se anastomoseiam em relações políticas, simbólicas, ambientais, econômicas, dentre outras, os compartimentos espaciais subjacentes a cada conjunto de relações se delineariam, portanto, na forma do território, do lugar, da região e daí por diante conforme o caráter da relação constituída. É nesse sentido que Tuan (1983:6) vai dizer que "o que começa como espaço indiferenciado transforma-se em lugar à medida que o conhecemos melhor e o dotamos de valor".

De fato, mas onde Moreira coloca paisagem e Tuan lugar, acrescentaríamos como relação espacial instituinte o espaço corporal desdobrado de imediato no espaço da corporeidade dos corpos. Assim como a percepção faz a mediação entre o noumeno e o fenômeno e deste para o seu entendimento,,$^{15}$ a corporeidade dos corpos, ora como algo de impreciso, antecede as frações mais definidas do

15 "A importância da percepção, embora seja a orientadora do comportamento humano, reside em seu papel intermediário - em geografía - entre o fenômeno e seu entendimento teórico" (Silva. 2000:20). 
espaço já impregnadas de um significado, ou seja, o território, a região, o lugar, e mesmo a paisagem, esposando ela própria a coisa em si e o acontecimento.

A paisagem supõe, portanto, um momento em que as variáveis estão mais definidas, o que se comprova pela indiferença e passividade do sujeito. É como se este não intervisse na paisagem a não ser por meio da faculdade perceptiva que a apreende. Todavia, no que se refere a um espaço percebido o agente se funde com a paisagem, redimensionando e a desdobrando em múitiplas outras paisagens a cada série de experiências. coexistindo com as sucessivas paisagens que se estendem para além de seu campo perceptivo, ou seja, pela paisagem apreendida pelo conjunto de corpos, conforme a variedade de perspectivas cujo horizonte temporal mescla presente, passado e futuro num único enlace de tempo, entrecruzando sentido e significado, caracterizando aquilo que Santos (2002:159) qualificou como eixos das sucessões e das coexistências. É nesse sentido que Merleau-Ponty (1975b:309), em alusão à arte de Cézanne, vai dizer "a paisagem se pensa em mim e sou sua consciência".

Estando claras tais evidências e para apaziguar o desconforto diante de algumas (propositais) redundâncias, no que se refere ao concurso da experiência perceptível na constituição de um espaço, abramos um parêntesis: paisagem e espaço corporal ou percebido são uma e a mesma coisa, contanto que o sujeito seja co-partícipe de seu movimento e reprodução. Aqui não nos interessa invalidar quaisquer categorias de análise. Entretanto, algumas abordagens geográficas se encontram tão contaminadas pelas tradições cartesiana e positivista que se faz necessário deslocar-lhes o foco para que possamos integrar-lhes os termos. O que a geografia tem feito é dotar a paisagem de significados estritos, extraindo-lhe sínteses para torná-la inteligível, porém opaca a uma intersubjetividade, desdobrandoa assim em outras dimensões positivas do espaço.

Urge reconhecer uma concepção de paisagem que contemple o sujeito encarnado num corpo, franqueado a uma corporeidade dos corpos (outro nome para espacialidade). "O problema é compreender relações singulares que se tecem entre as partes da paisagem ou entre a paisagem e mim enquanto sujeito encarnado, e pelas quais um objeto percebido pode concentrar em si toda uma cena, ou tornarse a imago de todo um segmento de vida" (MERLEAU-PONTY, 1999:84). Deste modo, cada paisagem estaria reversivelmente suscetível de muitas outras sensações além da consciência de um observador localizado num momento e local dado, e como tal passível de múltiplos sentidos e significações.

Nesse caso. ao visualizarmos uma paisagem a acariciamos de mesma sorte, interagimos em seu espetáculo sem que ela se encerre como estrado, a saboreamos pelo aroma que ela exala e vocifera, a ouvimos tanto pelas recordações que nos invade como pelo estardalhaço de suas cicatrizes históricas, dotamo-la de um significado deduzido do sentido que ela nos devolve e envolve. Ela nos abriga em suas chagas, o modo como se deteriora e nos torna cambiantes, nos contamina 
com um pavor que não é propriamente seu. mas o refletido de nossa opulência.

Resumo: Tentando romper com a idéia de um espaço único e absoluto e superar o impasse entre sujeito e objeto, Merleau-Ponty propõe um espaço como superfície da existência, apreéndido por meio da experiência perceptível. O presente artigo objetiva explicitar o quanto a obra de Merleau-Ponty pode ser relevante à investigação espacial em Geografia ou, mais precisamente, que perspectivas sua abordagem lenomenológica abre para uma leitura geográfica do espaço. sobretudo no que se refere ao estudo da paisagem.

Palavras-chave: corpo, espaço, paisagem, ser. existêncíı.

FROM BODY TO SPACE: CONTRIBUTIONS FROM MAURICE MERLEAU-PONTY TO GEOGRAPHY

Abstract: Trying to brust the idea of an unique and absolute space and overcome the impasse between subject and object. Merleau-Ponty proposes space as the existence's surface, apprehended by means of the perceptive experience. The current article has the purpose of portaying how much the work of Merleau-Ponty can be relevant to spatial research in Geography or, more accuretly, what perspectives his phenomenologic approach open for a geographical reading of space, especially when refered to landscape studies.

Keywords: body, space, landscape, being, existence.

\section{BIBLIOGRAFIA}

CERTEAU, Michel de. 2003. A Invenção do Cotidiano: l. arlès de fazer. Petrópolis: Vozes.

CHAUÍ, Marilena. 2002. Experiência do Pensamento: ensaios sobre a obra de Merlean Ponty. São Paulo: Martins Fontes.

COÊLHO, Ildeu M. 2003. "A Liberdade em Sartre”. In: PEIXOTO, A. J. (org.). Concepções Sobre a Fenomenologia. Goiânia: Editora UFG.

HUSSERL, Edmund. 1989. Meditações Cartesianas. Porto: Rés.

LIMA, Elias Lopes de. 2007. A Reinvençāo da Corporeidade: o cotejo entre a tradição moderna e a tradição indigena. Niterói, 209f, mimeo. Dissertação (Mestrado em Geografia) - PPGEO/UFF. iviterói.

MERLEAU-PONTY, Maurice. 2006. A Estrutura do Comportamento. Săo Paulo: Martins Fontes.

2005. O Visíel e o Imvisivel. São Paulo: Perspectiva.

2000. A Natureza. São Paulo: Martins Fontes.

1999. Fenomenologia da Percepcrão. São Paulo: Martins Fontes. 
. 1975a. "O Filósofo e sua Sombra". In: Textos Escolhidos (Coleção Os Pensadores). São Paulo: Abril Cultural.

1975b. “A Dúvida de Cézanne”. In: Textos Escolhidos (Coleção Os Pensadores). São Paulo: Abril Cultural.

MICHELAZZO, José Carlos. 2003. "Corpo e Tempo". In: Castro, Dagmar S. P. et. al. (orgs.). Corpo e Existência. São Bernardo do Campò: UMESP/FEMPEC.

MOLES, Abraham A. 1981. Teoria dos Objetos. Rio de Janeiro: Edições Tempo Brasileiro.

MOREIRA, Ruy. 2002. Teses para uma Geografia do Trabalho. Revista Ciência Geográfica. Bauru: AGB-Bauru, nº. 22, p. 19-23.

SANTOS, Milton. 2002. A Natureza do Espaço: técnica e tempo. razão e emoção. São Paulo: EDUSP.

SARTRE, Jean Paul. 1997. O Ser e o Nada: ensaios de ontologia fenomenológica. Petrópolis: Vozes.

SILVA, Armando Corrêa da. 2000. A Aparência, o Ser e a Forma (Geografia e Método). GEOgraphia, Niterói: UFF/EGG, ano II, nº. 3. p. 7-25.

TUAN, Yi Fu. 1983. Espaço e Lugar: a perspectiva da experiência. São Paulo: Difel. 